\title{
Triggering of viral RNA sensors induces CD55 expression on synovial fibroblasts
}

\author{
Olga N Karpus ${ }^{1 *}$, Kirstin M Heutinck ${ }^{1,2}$, Paul JM Wijnker ${ }^{1}$, Paul Peter Tak ${ }^{3}$, Jorg Hamann ${ }^{1}$ \\ From 6th European Workshop on Immune-Mediated Inflammatory Diseases \\ Nice, France. 23-25 November 2011
}

\section{Background}

CD55 (decay-accelerating factor) is a complement-regulatory protein, which is highly expressed by fibroblast-like synoviocytes (FLS). CD55 is also a ligand for CD97, an adhesion-type $\mathrm{G}$ protein-coupled receptor abundantly present on leukocytes. We recently showed that lack of either CD55 or CD97 ameliorates disease in murine collageninduced and $\mathrm{K} / \mathrm{BxN}$ serum transfer models of arthritis (Arthritis Rheum. 2010 Apr;62(4):1036-42). Little is known regarding the regulation of CD55 expression in FLS. We therefore investigated the effect of Toll-like receptors ligation and pro-inflammatory cytokines on CD55 expression.

\section{Materials and methods}

Synovial fibroblasts, obtained from biopsy samples of arthritis patients, were cultured and stimulated with cytokines (TNF, IFN $\gamma$, IL-1 $\beta$, IL-6, IFN $\alpha$ ) or TLR ligands (LTA, poly(I:C), LPS, imiquimod, CpG). Expression of CD55 was measured by flow cytometry using domain-specific monoclonal antibodies and recombinant CD97-loaded fluorescent beads. Chloroquine was used to inhibit TLR3 activity. Upregulation and functionality of dsRNA sensors in response to poly(I:C) or 5'-triphosphate RNA was analyzed by PCR. Apoptosis was measured by PI/annexinV staining and was blocked with the pan-caspase inhibitor Q-VD$\mathrm{OPH}$.

\section{Results}

Cultured synovial fibroblasts of patients with rheumatoid arthritis (RA), osteoarthritis, psoriatic arthritis, and spondylarthritis express equal amount of CD55. Stimulation of RA-FLS with IL-1 $\beta(\mathrm{p}=0.02)$ and poly(I:C) $(\mathrm{p}=0.001)$ induced a significant upregulation of CD55. Engagement of TLR3 by the dsRNA analog poly(I:C) was confirmed using chloroquine, an inhibitor of endosomal acidification that impairs TLR3 signaling. Synovial fibroblasts also expressed the cytoplasmic dsRNA sensors melanoma differentiation-associated gene 5 (MDA5) and retinoic acidinducible gene I (RIG-I). Stimulation of these receptors with either poly(I:C) or 5'-triphosphate RNA induced CD55 expression, but, in case of MDA5, also induced significant cell death $(\mathrm{p}<0.001)$ that was caspase-dependent. Upregulation of CD55 in response to dsRNA receptor activation increased the binding capacity of synovial fibroblasts for CD97-loaded beads.

\section{Conclusions}

We identify dsRNA as a potent inducer of CD55 upregulation on synovial fibroblasts. Our findings suggest that CD55 induction by viral dsRNA or dsRNA may facilitate the accumulation of CD97-expressing inflammatory immune cells in the synovial tissue.

\section{Author details \\ ${ }^{1}$ Dept. of Experimental Immunology, Academic Medical Center, Amsterdam, The Netherlands. ${ }^{2}$ Renal Transplant Unit, Academic Medical Center, Amsterdam, The Netherlands. ${ }^{3}$ Division of Clinical Immunology and Rheumatology, Academic Medical Center, Amsterdam, The Netherlands.}

Published: 23 November 2011

doi:10.1186/1479-5876-9-S2-P41

Cite this article as: Karpus et al.: Triggering of viral RNA sensors induces CD55 expression on synovial fibroblasts. Journal of Translational Medicine 2011 9(Suppl 2):P41. 